\title{
Effects of N-Acetylcysteine on Renal Hemodynamics in Contrast Media-Induced Nephropathy
}

\author{
Stefan Krzossok Claude Braun Elizabeth Weiss Simone Hoeger \\ Peter Schnuelle Urs Benck Rainer Birck Bernhard K. Krämer Uwe Göttmann \\ Fifth Medical Department, Nephrology/Endocrinology/Rheumatology, University Medical Center Mannheim, \\ University of Heidelberg, Mannheim, Germany
}

\section{Key Words}

Renal blood flow $\cdot$ Medullary blood flow $\cdot$ Contrast media $\cdot$ Endothelin

\begin{abstract}
Background: $\mathrm{N}$-acetylcysteine (NAC) has been proposed to prevent radiocontrast nephropathy in high-risk patients. Methods: The effect of single-dose and prolonged administration of NAC before application of either the ionic, highosmolar radiocontrast agent diatrizoate sodium (DTZ) or the nonionic, low-osmolar radiocontrast agent iohexol $(\mathrm{IOH})$ in a rat model combining uninephrectomy, salt depletion, and administration of indomethacin was explored. Arterial blood pressure and total, cortical, and medullary blood flow were continuously recorded in anesthetized Sprague-Dawley rats. Results: NAC had no effect on renal hemodynamics in control rats. Both DTZ and IOH induced biphasic changes in renal blood flow and cortical renal blood flux and persistently reduced medullary blood flux. Neither single-dose nor prolonged administration of NAC prevented the hemodynamic changes following administration of DTZ or IOH, respectively. Acute prophylactic administration of NAC prevented increased urinary ET excretion after injection of $\mathrm{IOH}$ and, to a smaller degree, of DTZ. Both an ionic, high-osmolar (DTZ) and
\end{abstract}

a nonionic, low-osmolar $(\mathrm{IOH})$ radiocontrast agent induce marked changes in renal hemodynamics in salt-depleted rats treated with indomethacin. Conclusions: Renal perfusion is not affected by NAC application in a model of experimental contrast nephropathy in rats. Other effects of NAC might thus account for the presumed renoprotective properties.

Copyright $\odot 2011$ S. Karger AG, Basel

\section{Introduction}

The term contrast media nephropathy is widely used to refer to the reduction in renal function induced by radiocontrast media. It is generally defined as an impairment in renal function (increase in serum creatinine by more than $25 \%$ or at least $0.5 \mathrm{mg} / \mathrm{dl}$ ) occurring within 3 days following the intravascular administration of contrast media and the absence of alternative etiology [1]. Patients at increased risk include those with congestive heart failure, renal impairment, and diabetes mellitus, especially in combination [2]. It is associated with extended hospital stays as well as increased morbidity and mortality [3-7]. Although the pathogenesis of contrast media nephropathy is incompletely understood, reduced synthesis of prostaglandin and NO, alteration of renal hemo-

\section{KARGER}

Fax +41613061234 E-Mail karger@karger.ch www.karger.com
(C) 2011 S. Karger AG, Basel

$1420-4096 / 11 / 0342-0125 \$ 38.00 / 0$

Accessible online at:

www.karger.com/kbr
Uwe Göttmann, MD, PhD

Fifth Medical Department, Nephrology/Endocrinology/Rheumatology

University Medical Center Mannheim, University of Heidelberg

Theodor-Kutzer-Ufer 1-3, DE-68167 Mannheim (Germany)

Tel. +49621383 3370, E-Mail uwe.goettmann@umm.de 
dynamics resulting in medullary ischemia, and generation of reactive oxygen species leading to renal tubular toxicity seem to play a role $[8,9]$. Several approaches to prevent contrast nephropathy have been reported, including calcium-channel blockers, theophylline, dopamine, and endothelin receptor antagonists, without major success [10]. At present, prophylactic treatment regimes, mainly including hydration with isotonic saline or bicarbonate and premedication with NAC prior to the application of radiocontrast medium, have been reported to ameliorate contrast media-induced nephropathy [11-16]. Regarding premedication with NAC, most meta-analyses of these rather heterogeneous studies showed that NAC significantly reduces the risk of contrast media-induced nephropathy [17-19].

Besides this beneficial effect on contrast media-induced nephropathy, NAC has been shown to attenuate ischemic renal failure [20] and to prevent gentamicin and cyclosporine nephrotoxicity in experimental animals [21, 22]. The nephroprotective properties have been attributed to the scavenging of reactive oxygen species, either directly or indirectly via improvement of the intracellular antioxidative status [23]. In addition, NAC ameliorates renal vasoconstriction induced by the radiocontrast agent iothalamate, an effect that seems to be mediated by mechanisms other than nitric oxide and prostaglandins [24]. The molecular mechanisms responsible for the vasodilatory effects of NAC remain uncertain. Endothelin-1 (ET1 ), one of the most potent endogenous vasoconstrictors, is released from renal tubular cells upon exposure to the radiocontrast agents iohexol or diatrizoate [25]. In dogs with pacing-induced heart failure, significant increases in both plasma and urinary ET were observed during and after intravenous radiocontrast administration [26]. However, a possible influence of NAC pretreatment on renal ET release has thus far not been studied.

Therefore, the aim of the present study was to investigate the influence of treatment with NAC prior to the administration of either the ionic, high-osmolar radiocontrast agent osmodiatrizoate sodium (DTZ) or the non-ionic, low-osmolar radiocontrast agent iohexol $(\mathrm{IOH})$ on renal hemodynamics and urinary ET excretion in rats.

\section{Materials and Methods}

All procedures were performed according to the 'Guide for the Care and Use of Laboratory Animals' published by the National Academy of Sciences and were approved by the local authorities (Regierungspräsidium Karlsruhe). Experiments were performed in male Sprague-Dawley rats weighing between 250 and $350 \mathrm{~g}$. Animals were kept under standard conditions. A previously described rat model combining uninephrectomy, salt depletion, and administration of indomethacin, leading to increased ischemic susceptibility of the renal medulla $[27,28]$, was chosen to investigate the influence of contrast media application on renal hemodynamics. 3 weeks prior to contrast media application, rats underwent right-sided nephrectomy. One week prior to contrast media application, salt depletion was achieved by three daily furosemide injections $(2 \mathrm{mg} / \mathrm{kg} / \mathrm{i} . \mathrm{p}$.) followed by a sodium-deficient diet $(\mathrm{NaCl}<0.008 \%)$ for 1 week. Sodium depletion was used to aggravate the hemodynamic changes induced by indomethacin and contrast media application by stimulating the renin-angiotensin system via the 'tubular glomerular feedback' loop.

\section{Hemodynamic Studies}

On the day of the experiments, animals were anesthetized with Inactin ${ }^{\circledR}(100 \mathrm{mg} / \mathrm{kg}$ i.p. $)$ and placed on a heating table to keep their body temperature constant. Arterial and venous catheters $\left(\mathrm{PE}_{50}\right)$ were inserted into the femoral vessels and external jugular vein. Indomethacin (Sigma Chemical Co., St. Louis, Mo., USA) was administered as a single intravenous bolus injection $(5 \mathrm{mg} / \mathrm{kg} \mathrm{KG})$ $1 \mathrm{~h}$ before the start of the hemodynamic measurements. An intravenous infusion of isotonic saline with albumin at a concentration of $5 \mathrm{~g} / \mathrm{dl}$ was then commenced at a rate of $3 \mathrm{ml} / \mathrm{h}$ throughout all experiments. Measurement of mean arterial blood pressure (MAP) was performed via the arterial line with a Statham pressure transducer $\mathrm{P} 23 \mathrm{Db}$ and a Gould pressure processor and continuously monitored. An ultrasonic transit-time flow probe (1RB, Transonic Systems Inc., Ithaka, N.Y., USA) was placed around the left renal artery for measurement of renal blood flow (RBF). The signals were transmitted to a transit time flowmeter (T106, Transonic Systems). The left kidney was exposed by a left subcostal flank incision and immobilized in a plastic cup with its dorsal side up and embedded in cotton wool soaked in saline. For determination of cortical blood flux (CBF), a blunt superficial laser Doppler probe (P10B Prisma, Moore Instruments Ltd., Fa. Lawrenz, Sulzbach, Germany) was placed on the kidney surface and covered by body warm mineral oil. Outer medulla blood flux (MBF) was measured by inserting a fine needle laser Doppler probe (P10B Prisma, Moore Instruments) into the outer medulla. Both probes were mounted on micromanipulators to avoid movement artifacts. The signals of the two probes were transmitted to a laser flowmeter (MBF 3D, Moore Instruments). Validation of the transit time and laser Doppler methods are given elsewhere $[29,30]$. The correct positioning of the medulla probe within the outer medulla was assured macroscopically at the end of each experiment. The urinary bladder was cannulated through a small abdominal incision to obtain urine sampling for creatinine, sodium and ET-1. After the surgical procedure, a 30-60-min equilibration time was allowed to reach baseline values. Hemodynamic responses to DTZ, an ionic, high-osmolar contrast agent $\left(370 \mathrm{mg} \mathrm{J} / \mathrm{ml}\right.$; Peritrast ${ }^{\circledR}$; Dr. Köhler AG, Germany), and to $\mathrm{IOH}$, a nonionic, low-osmolar agent $(350 \mathrm{mg} \mathrm{J} / \mathrm{ml}$; Omnipaque $^{\circledR}$; Schering AG, Germany), injected intra-arterial as a bolus, were then recorded in the different experimental groups:

Group 1 (VEH; $n=10)$. Animals received isotonic saline (i.v.) as vehicle at 0 and $5 \mathrm{~min}$.

Group 2 (NAC; $n=7)$. Animals received NAC (300 mg/kg i.v.) at time 0 and isotonic saline as vehicle at time $5 \mathrm{~min}$ to evaluate the hemodynamic effects of NAC given alone. 
Group 3 (DTZ; $n=7)$. Animals received isotonic saline as vehicle at time 0 and DTZ ( $5 \mathrm{ml} / \mathrm{kg}$ i.a.) at time $5 \mathrm{~min}$.

Group $4(\mathrm{NAC}+\mathrm{DTZ} ; n=7)$. Animals received NAC (300 mg/

$\mathrm{kg}$ i.v.) at time 0 and DTZ (5 ml/kg i.a.) at time $5 \mathrm{~min}$.

Group $5(\mathrm{IOH} ; n=7)$. Animals received isotonic saline at time 0 and $\mathrm{IOH}(8.2 \mathrm{ml} / \mathrm{kg}$ i.a. $)$ at time $5 \mathrm{~min}$.

Group $6(\mathrm{NAC}+\mathrm{IOH} ; n=7)$. Animals received NAC (300 mg/ $\mathrm{kg}$ i.v. $)$ at time 0 and $\mathrm{IOH}(8.2 \mathrm{ml} / \mathrm{kg}$ i.a. $)$ at time $5 \mathrm{~min}$.

To evaluate the potential effect of a prolonged pretreatment of NAC, starting two days prior to the administration of radiocontrast media, three additional groups were studied:

Group 7 (cNAC; $n=7$ ). Animals received an intraperitoneal injection of NAC $(300 \mathrm{mg} / \mathrm{kg})$ twice daily on days -2 and -1 . On day 0 , isotonic saline as vehicle was administered, and hemodynamic response recorded, as described above.

Group $8(c N A C+D T Z)$. Animals received an intraperitoneal injection of NAC (300 mg/kg) twice daily on days -2 and -1 , followed by the i.a. application of DTZ, as described above.

Group $9(\mathrm{cNAC}+\mathrm{IOH})$. Animals received an intraperitoneal injection of NAC $(300 \mathrm{mg} / \mathrm{kg})$ twice daily on days -2 and -1 , followed by the i.a. application of $\mathrm{IOH}$, as described above.

All the above-mentioned parameters were continuously recorded with a multi-channel Gould Brush 2600 recorder for 30 min following administration of NAC, contrast media, or isotonic saline, respectively. Before and after the hemodynamic studies, urine samples were collected for measurement of ET (ET-1). Animals were sacrificed at the end of the experiments. Values are given as changes from baseline in percent.

\section{Urinary Endothelin Measurement}

After acidification and extraction of ET on C18 columns, ET concentration in urine was determined by radioimmunoassay with an anti-ET antibody and ${ }^{125}$ I-ET (Nichols Institute Diagnostics B.V., Wychen, The Netherlands).

\section{Data Calculation and Statistical Evaluation}

Data are reported as means \pm SEM. Statistical evaluation of the data was performed by using the statistical program package StatsDirect (version 2, 2, 4). We used analysis of variance with Bonferroni correction for multiple comparisons of means among groups and the paired t test for comparisons within groups. Differences between the means were considered to be significant at $\mathrm{p}<0.05$

\section{Results}

There was no significant difference in mean arterial pressure (MAP) in rats treated with single or prolonged administration of NAC (median $104 \mathrm{~mm} \mathrm{Hg}$, data not shown). Baseline renal blood flow (RBF) was not different between the groups (median $8.1 \mathrm{ml} / \mathrm{min}$ ). Administration of DTZ and IOH resulted in a significant increase of $\mathrm{RBF}$ at $5 \min (\mathrm{DTZ}+12 \%, \mathrm{p}<0.05 ; \mathrm{IOH}+21 \%, \mathrm{p}<0.05)$, compared to baseline (fig. 1, 2). After the initial increase, $\mathrm{RBF}$ dropped in the DTZ group and remained below baseline values throughout the experiment (DTZ $-17 \%$ after 25 and $30 \mathrm{~min}, \mathrm{p}<0.05$ ), whereas in $\mathrm{IOH}$-treated animals no significant decrement after application could be observed, when compared to baseline. This decrement of RBF was significantly more pronounced after DTZ compared to $\mathrm{IOH}$ at 15,20 and $25 \mathrm{~min}$.

Administration of DTZ and IOH was followed by a biphasic change in CBF (fig. 1, 3). Five minutes after application CBF was increased (DTZ $+12 \%, p<0.05$; IOH $+6 \%, \mathrm{p}<0.05)$ as compared to baseline values. During the next $25 \mathrm{~min}$, a mild decrement in CBF was observed. Only in the DTZ group CBF remained depressed up to 20 min after contrast application.

In contrast to total and cortical blood flux, both DTZ and $\mathrm{IOH}$ led to a monophasic decrease in medullary blood flow (MBF) (fig. 1, 4). The maximum reduction in MBF occurred after $10 \mathrm{~min}$ (DTZ -21\%, p $<0.05, \mathrm{IOH}$ $-19 \%, p<0.05)$. MBF remained decreased till the end of measurement in the DTZ group. In the IOH-treated group, the significant decrease lasted until $25 \mathrm{~min}$ after application. Effects on MBF were not statistically different between DTZ and $\mathrm{IOH}$.

The acute administration of NAC had no effect on renal hemodynamics (group 2, data not shown). In addition, the biphasic response seen after the administration of DTZ and IOH was not affected by a single dose of NAC. Likewise, the effect of DTZ and IOH on cortical and medullary blood flux was not modulated by NAC pretreatment.

The calculated vascular resistances did not indicate a change in vascular tone of macro- or microvasculature after the acute administration of NAC. Prolonged administration of NAC did not alter renal hemodynamic in the DTZ and IOH groups (fig. 2-4). Absolute changes of $\mathrm{RBF}, \mathrm{CBF}$ and $\mathrm{MBF}$ are depicted in figure 5.

There was no significant difference in urine flow. Urinary excretion of ET-1 was significantly increased after $\mathrm{IOH}$ and DTZ administration ( $<$ < 0.05) (fig. 6). Singledose NAC pretreatment significantly decreased urinary excretion of ET in the IOH group (p<0.05). In the DTZ group a slight, though not significant decrease was observed ( $p \geq 0.29$ ). Prolonged administration of NAC, on the other hand, had no influence on urinary excretion of ET.

\section{Discussion}

This study demonstrates that the ionic, high-osmolar DTZ and the nonionic, low-osmolar IOH induce comparable, long-lasting changes in renal hemodynamics in 


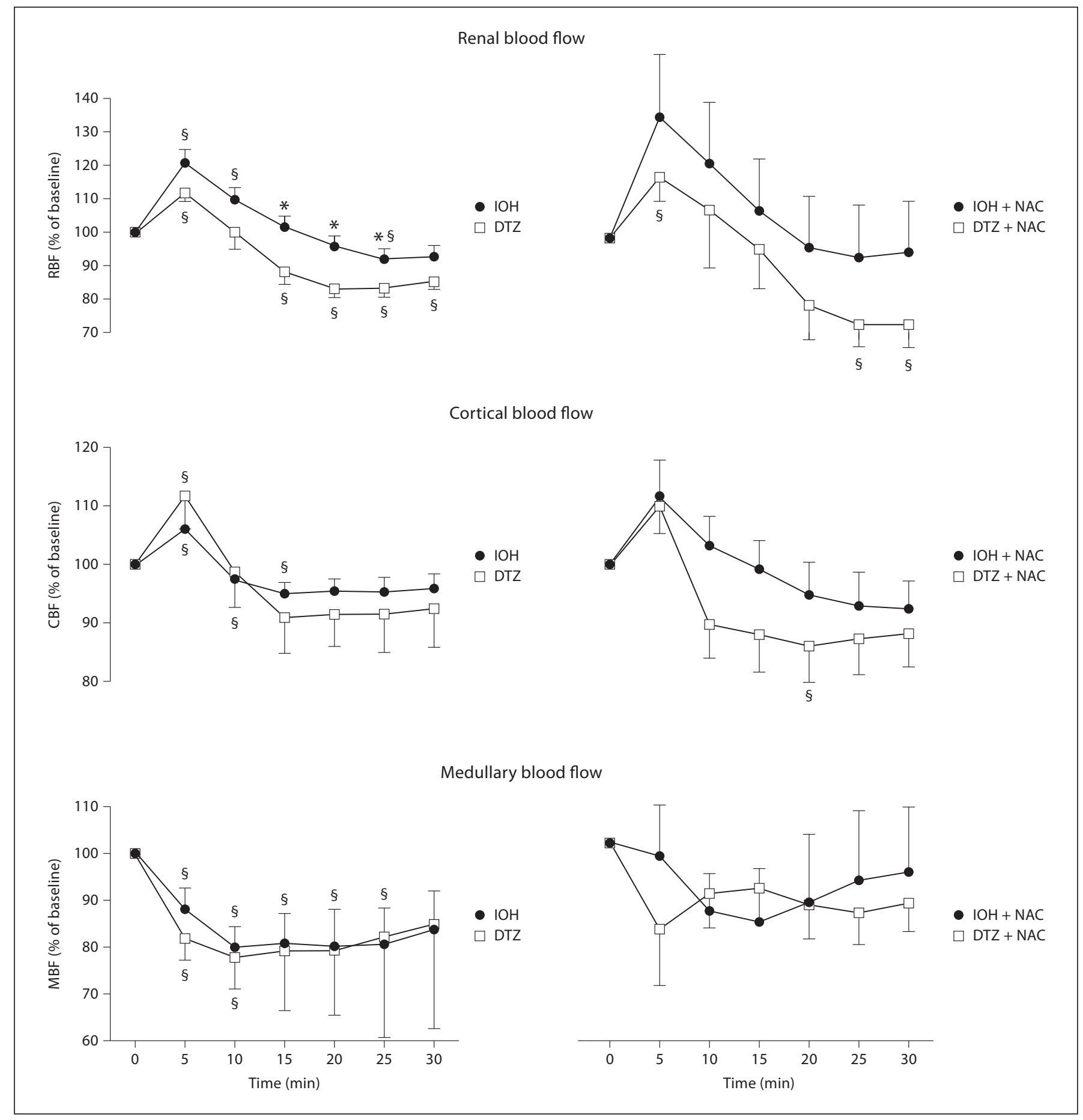

Fig. 1. Renal, cortical and medullary blood flow after i.a. application of DTZ (5 ml/kg) or IOH $(8.2 \mathrm{ml} / \mathrm{kg}) \mathrm{on}$ the left side and after i.v. application of NAC $(300 \mathrm{mg} / \mathrm{kg})$ followed by i.a. application of DTZ $(5 \mathrm{ml} / \mathrm{kg}) \mathrm{or} \mathrm{IOH}$ $(8.2 \mathrm{ml} / \mathrm{kg})$ after $5 \mathrm{~min}$ on the right side. ${ }^{\S}$ Significant difference compared to baseline. ${ }^{*}$ Significant difference IOH compared to DTZ ( $<<0.05)$. 


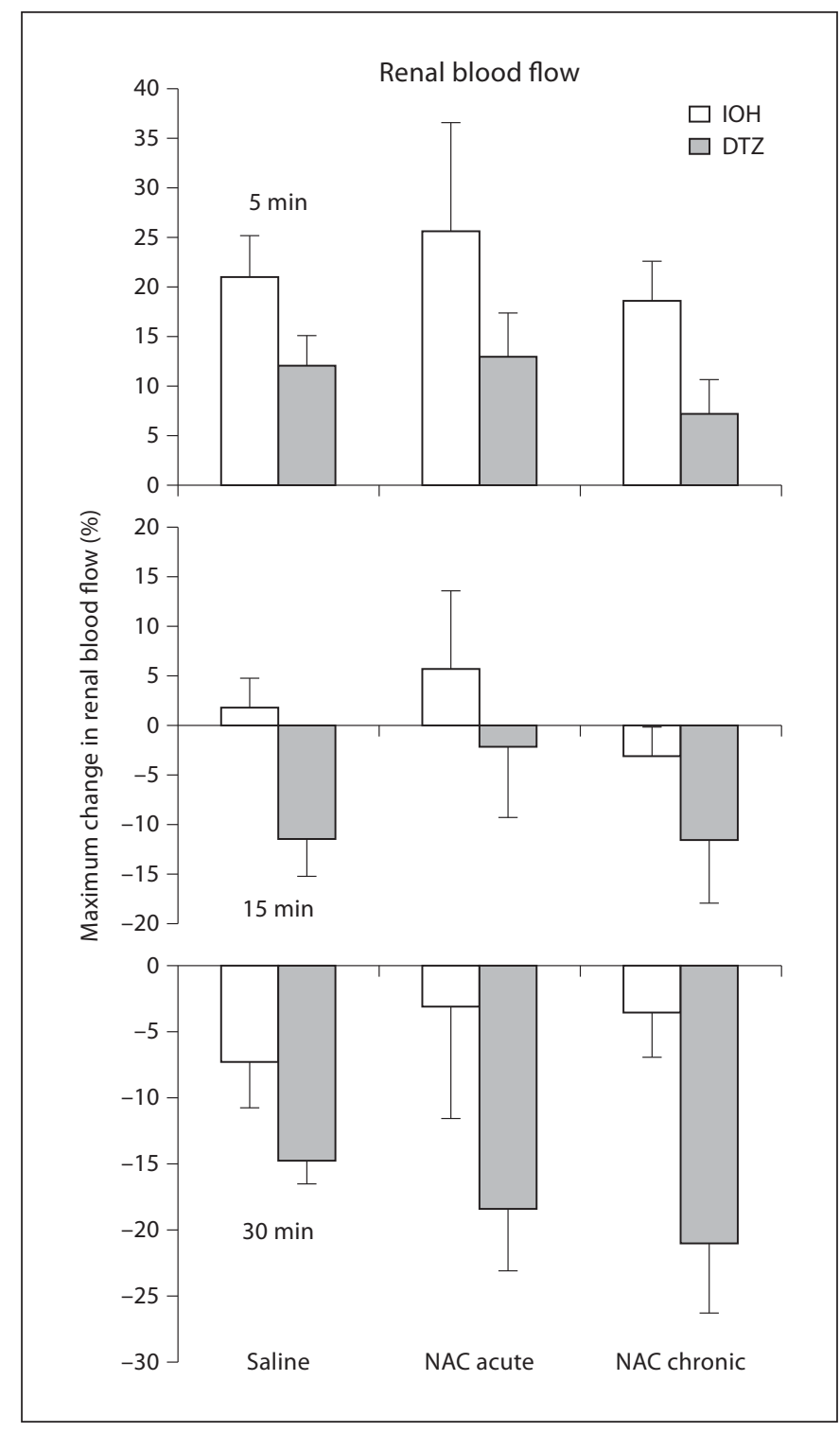

Fig. 2. Maximal changes in renal blood flow 5, 15 and $30 \mathrm{~min}$ after i.a. application of DTZ $(5 \mathrm{ml} / \mathrm{kg})$ or IOH $(8.2 \mathrm{ml} / \mathrm{kg})$ and after i.v. application of saline (saline), after i.v. application of $300 \mathrm{mg} /$ $\mathrm{kg}$ NAC (NAC acute) followed by DTZ or IOH and after prolonged (NAC chronic) i.p. application of NAC (300 mg/kg b.i.d.) over 2 days followed by DTZ or IOH. No significant difference.

salt-depleted rats treated with a cyclo-oxygenase inhibitor. In contrast to total and cortical blood flow, which exhibited a biphasic change upon challenge with the contrast media, medullary blood flow was markedly and persistently depressed after administration of DTZ or IOH. Neither single-dose nor prolonged administration of NAC was able to prevent microcirculatory changes after

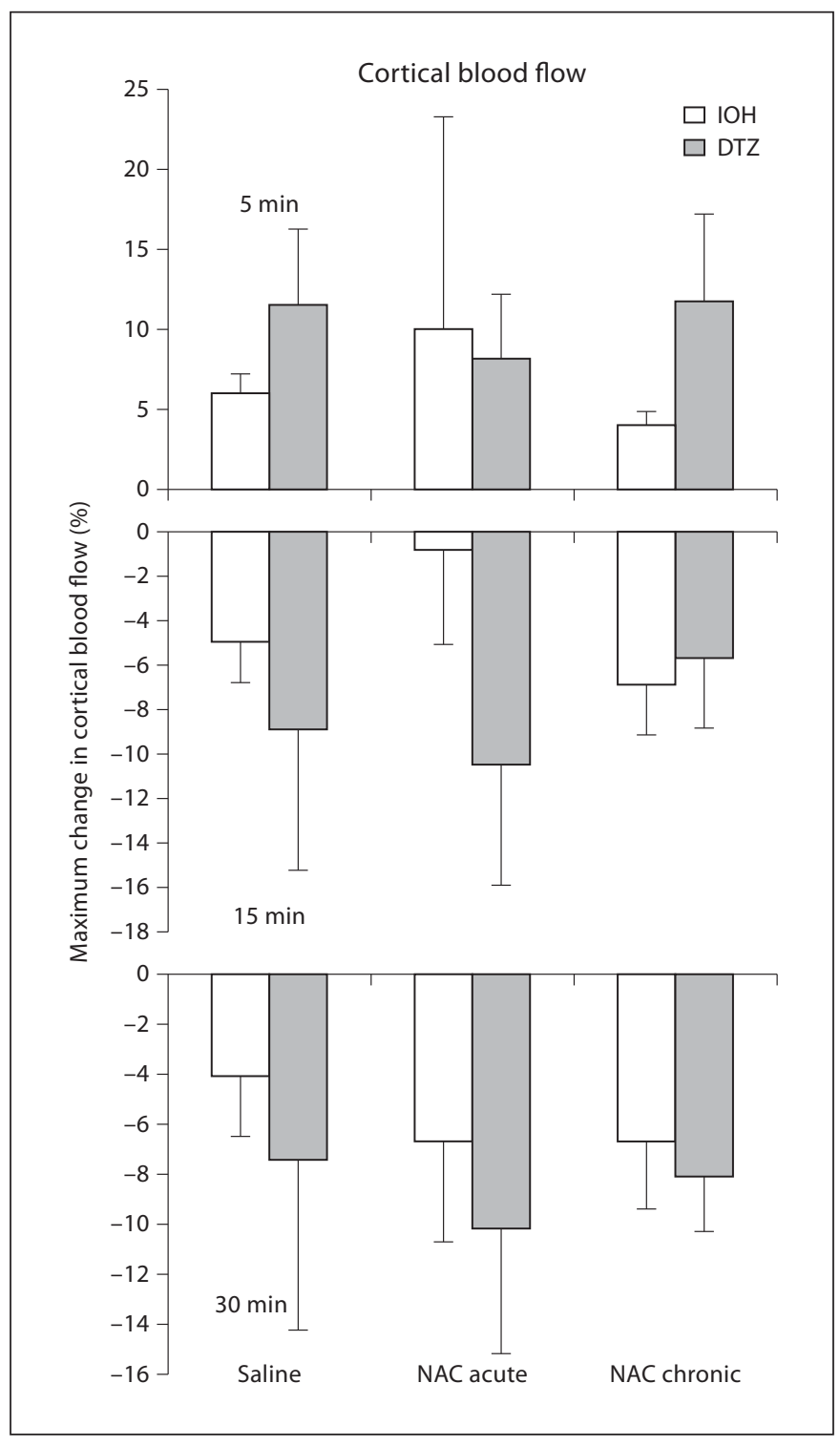

Fig. 3. Maximal changes in cortical blood flow 5, 15 and $30 \mathrm{~min}$ after i.a. application of DTZ $(5 \mathrm{ml} / \mathrm{kg})$ or IOH $(8.2 \mathrm{ml} / \mathrm{kg})$ and application of saline (saline), after i.v. application of $300 \mathrm{mg} / \mathrm{kg} \mathrm{NAC}$ (NAC acute) followed by DTZ or IOH and after prolonged (NAC chronic) i.p. application of NAC $(300 \mathrm{mg} / \mathrm{kg}$ b.i.d.) over 2 days followed by DTZ or IOH. No significant difference $(\mathrm{p}>0.05)$. exposure to contrast agents. A pathogenic role of ET for contrast-induced hemodynamic changes is not supported by the present findings, as high-dose pretreatment with NAC prevents increased urinary ET secretion, without affecting renal perfusion.

A reduction in renal medullary perfusion caused by a direct vasoconstrictive effect of contrast media and tox- 


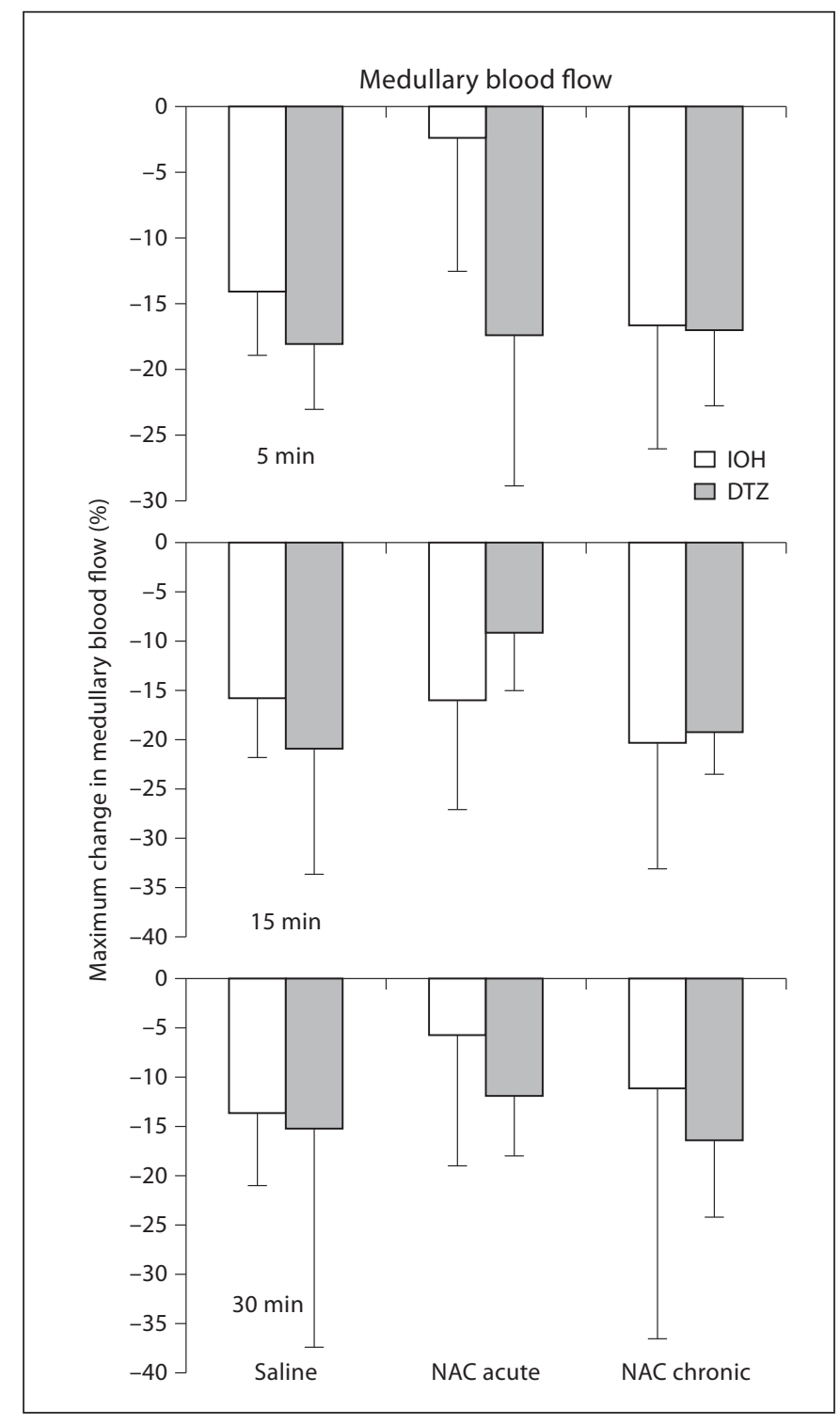

Fig. 4. Maximal changes in medullary blood flow 5, 15 and $30 \mathrm{~min}$ after i.a. application of DTZ $(5 \mathrm{ml} / \mathrm{kg})$ or IOH $(8.2 \mathrm{ml} / \mathrm{kg})$ and after i.v. application of saline (saline), and after i.v. application of 300 $\mathrm{mg} / \mathrm{kg}$ NAC (NAC acute) followed by DTZ or IOH, and after prolonged (NAC chronic) i.p. application of NAC (300 mg/kg b.i.d.) over 2 days followed by DTZ or IOH. No significant differences $(\mathrm{p}>0.05)$

ic effects on the tubular cells are generally regarded as the main pathogenic factors underlying radiocontrast nephropathy [9, 31-33]. Improving renal hemodynamics may thus be able to prevent renal functional deterioration after administration of iodinated contrast media. NAC, a small molecule with potent antioxidant properties, has been shown to exert vasodilatory effects. Cone- sa et al. [34] studied NAC in acute renal failure induced by inferior vena cava occlusion, a model that causes reduced medullary blood flow. They found that NAC reduced outer medullary vasoconstriction, thus improving blood flow and recovery of renal failure. Furthermore, NAC showed protective effects on the extent of renal failure induced by inferior vena cava occlusion [20]. In a recent study, Heyman et al. [24] investigated the hemodynamic effects of NAC in rats given radiocontrast media. After intravenous administration of NAC, renal vasoconstriction induced by radiocontrast was partially reversed. The authors concluded that NAC has an important vasodilatory effect in the preconstricted renal vasculature. Taken together, these studies provide preliminary evidence that NAC is a vasodilatory agent that may protect against vasoconstriction in certain forms of renal disease.

However, the experimental setting chosen by Heyman et al. [24] does not reflect clinical reality, e.g. NAC is administered before contrast agents are given for diagnostic purposes. In the study by Heyman et al. [24], the effects of NAC were determined in rats pretreated with radiocontrast medium. The present study was therefore designed to investigate whether the acute or chronic administration of NAC prior to application of contrast media prevents hemodynamic deterioration in rat kidneys. As described in previous reports, administration of radiocontrast resulted in a biphasic change of total and cortical blood flow, characterized by a transient vasodilatation followed by a prolonged vasoconstrictor response $[35,36]$. In contrast, medullary blood flow was markedly and sustained decreased immediately after application of DTZ and IOH. Overall, the hemodynamic response to the nonionic, low-osmolar contrast medium $\mathrm{IOH}$ was less pronounced compared to the ionic, high-osmolar contrast medium DTZ. Several reports have reported a higher incidence of radiocontrast nephropathy in patients given ionic, high-osmolar contrast agents [37,38]. Interestingly, NAC seems equally effective in preventing renal functional deterioration, independent of the contrast agent used [39].

We found no evidence for a significant vasodilatory effect of pretreatment with NAC. The renal vascular resistance was calculated and no difference was found between the animals pretreated with NAC compared to those receiving no pretreatment. This observation is in opposition to previous reports, where interactions with the renin-angiotensin system [40] and the formation of nitric oxide $[20,34,41]$ were believed to be responsible for the hemodynamic effects of NAC. Heyman et al. [24] 

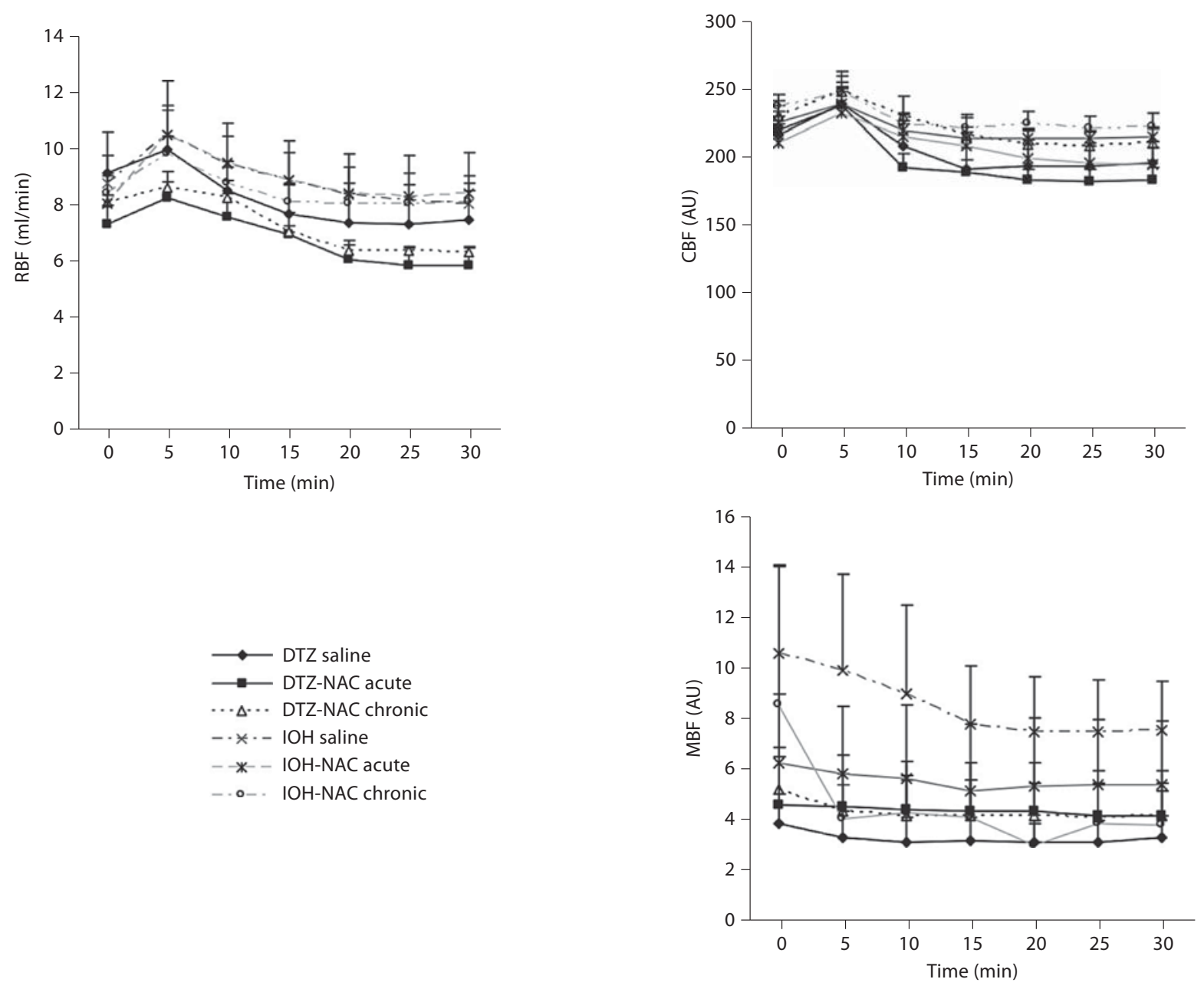

Fig. 5. Absolute changes in renal, cortical and medullary blood flow after i.a. application of DTZ $(5 \mathrm{ml} / \mathrm{kg})$ or IOH $(8.2 \mathrm{ml} / \mathrm{kg})$ and after i.v. application of saline (DTZ-saline, $\mathrm{IOH}$-saline), and after i.v. application of $300 \mathrm{mg} / \mathrm{kg}$ NAC followed by DTZ or IOH
(DTZ-NAC acute, IOH-NAC acute), and after prolonged i.p. application of NAC (300 mg/kg b.i.d.) over 2 days followed by DTZ or IOH (DTZ-NAC chronic, IOH-NAC chronic). For readability, significant changes are shown in figure 1.
Fig. 6. Urine concentration of ET in saline-treated rats, after i.a. application of DTZ $(5 \mathrm{ml} / \mathrm{kg})$ or IOH $(8.2 \mathrm{ml} / \mathrm{kg})$ and after i.v. application of NAC $(300 \mathrm{mg} / \mathrm{kg})$ followed by DTZ or IOH. ${ }^{*} \mathrm{p}<0.05$ $\mathrm{IOH}$ or DTZ vs. control group. ${ }^{\S} \mathrm{p}<0.05 \mathrm{NAC}+\mathrm{IOH}$ vs. $\mathrm{IOH}$ group.

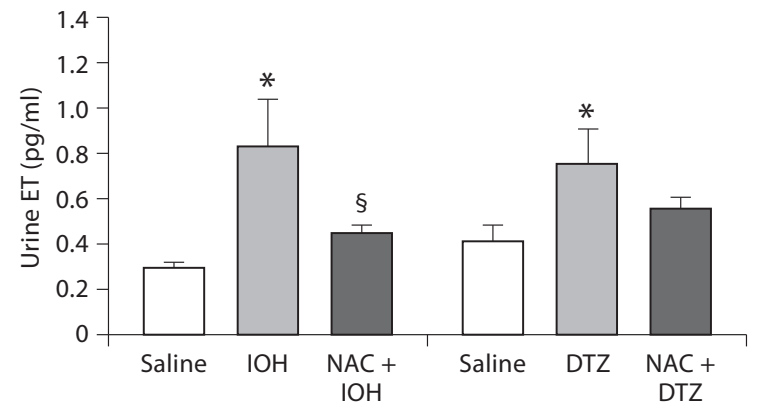


could show that the strongest vasodilatory effect of NAC was noted in animals with the most intense renal vasoconstriction; no effects were found in intact animals. They confirmed that NAC could partially reverse renal vasoconstriction induced by radiocontrast and angiotensin II, or during the inhibition of renal prostaglandin or NO production. Moreover, their study indicated that renal vasodilation may be mediated through mechanism other than NO and prostaglandins. Nitescu et al. [42] could not show an effect of NAC on renal hemodynamics in early ischemia-reperfusion injury in rat, but renal injury caused by arterial clamping was more severe than in the model chosen by Heyman. In an experimental model for prevention of renal tubular vacuolization after administration of $\mathrm{IOH}$, no beneficial effect of NAC could be observed [43].

A limitation of our study is that we did not perform a dose-response analysis of NAC pretreatment, but the dose used in the acute model was even higher than in other studies [20,34].

Most clinical trials and meta-analyses reporting on the beneficial effects of NAC in preventing radiocontrast nephropathy used serum creatinine as a surrogate end point of their trials, as changes in serum creatinine are thought to reflect the extent of renal injury as primary outcome. A recent study has shown that NAC administration in healthy volunteers decreases serum creatinine and increases GFR without any effect on cystatin C levels, questioning the positive results observed in clinical trials using serum creatinine as a surrogate marker for renal function [44].

ET is one of the most potent endogenous vasoconstrictors on a molar basis [45]. Several reports have documented a renal release of ET by radiocontrast agents and induction of medullary hypoperfusion and hypoxia via vasoconstrictory ET-A receptors [26, 46, 47]. In experimental animal models, radiocontrast-induced renal damage could be prevented by the administration of both selective ET-A receptor and combined ET-A/B receptor antagonists $[48,49]$. We found that NAC pretreatment, in the acute setting, prevented renal ET excretion after administration of IOH and, to a lesser degree, DTZ, without any effects on renal hemodynamics. Taken together, our findings strongly argue against a significant role of the ET system in the hemodynamic changes induced by radiocontrast agents. In a randomized clinical trial, Wang et al. [50] could not demonstrate a beneficial, but rather a deleterious effect of the nonselective ET receptor blocker SB 290670 on renal function after administration of contrast medium.
Besides influence on renal microcirculation, toxic and pro-oxidative effects on renal tubular cells are generally accepted as the main factors in the pathophysiology of contrast medium-induced nephropathy. Hypertonicity of contrast agents led to renal tubular apoptosis in vivo and in vitro [51, 52]. NAC failed to attenuate the radiocontrast-induced apoptosis in vitro [53]. New insights in the underlying pathogenesis of radiocontrast-induced nephropathy were shown in the work by Zager et al. [54]. They found no evidence for radiocontrast media-induced oxidative stress in vitro. Radiocontrast media-induced cytotoxicity thus might be dissociated from tubular cell oxidant stress. This would explain the failure of the antioxidant drug NAC in preventing contrast nephropathy in recent animal studies [24]. Compound-related toxicity appears to play the dominant pathogenic role, but the molecular basis for this observation remains unknown up to now. Recent work focused on the role of contrast agent viscosity in the pathophysiology of contrast media nephropathy [55-57], showing that high-viscous contrast agents perturb renal hemodynamics to a greater extent than low-viscous contrast agents and increase urine viscosity up to 50 -fold when different nonionic contrast agents were compared. Moreover, lowviscous contrast media have generally a higher osmolality that induces an osmodiuresis that facilitates renal elimination and prevents low flow rates in the tubulus. However, in our setting with a nonionic, low-osmolar contrast agent such as $\mathrm{IOH}$ and an ionic, high-osmolar contrast agent such as DTZ, we did not look at urine viscosity and could not detect a difference in urine volume as urine production was very low during the sampling period of only $30 \mathrm{~min}$. In a clinical setting, some studies indicate that contrast agents with higher viscosity might be associated with a higher incidence of contrast media nephropathy $[58,59]$, whereas others could not confirm these findings $[60,61]$.

In summary, both an ionic, high-osmolar (DTZ) and a nonionic, low-osmolar $(\mathrm{IOH})$ radiocontrast agent induce marked changes in renal hemodynamics in salt-depleted rats pre-treated with indomethacin. Although a single dose of NAC administered prior to contrast media prevents increased urinary ET excretion, renal perfusion is not affected by prophylactic NAC application. Other effects of NAC might thus account for the presumed renoprotective properties. 


\section{References}

$\checkmark 1$ Morcos SK, Thomsen HS, Webb JA: Contrast-media-induced nephrotoxicity: a consensus report. Contrast Media Safety Committee, European Society of Urogenital Radiology (ESUR). Eur Radiol 1999;9:16021613.

-2 Porter GA: Effects of contrast agents on renal function. Invest Radiol 1993;28(suppl 5):S1S5, discussion S6.

-3 Cohan RH, Dunnick NR: Intravascular contrast media: adverse reactions. AJR Am J Roentgenol 1987;149:665-670.

4 Shusterman N, Strom BL, Murray TG, Morrison G, West SL, Maislin G: Risk factors and outcome of hospital-acquired acute renal failure: clinical epidemiologic study. Am J Med 1987;83:65-71.

5 Levy EM, Viscoli CM, Horwitz RI: The effect of acute renal failure on mortality: a cohort analysis. JAMA 1996;275:1489-1494.

6 Kramer BK, Hoffmann U: Benefit of acetylcysteine for prevention of contrast-induced nephropathy after primary angioplasty. Nat Clin Pract Nephrol 2007;3:10-11.

$\checkmark 7$ Kramer BK, Kammerl M, Schweda F, Schreiber M: A primer in radiocontrastinduced nephropathy. Nephrol Dial Transplant 1999; 14:2830-2834.

$\checkmark 8$ Brezis M, Rosen S: Hypoxia of the renal medulla - its implications for disease. N Engl J Med 1995;332:647-655.

-9 Bakris GL, Lass N, Gaber AO, Jones JD, Burnett JC Jr: Radiocontrast medium-induced declines in renal function: a role for oxygen free radicals. Am J Physiol 1990;258:F115F120.

10 Murphy SW, Barrett BJ, Parfrey PS: Contrast nephropathy. J Am Soc Nephrol 2000;11: 177-182.

-11 Solomon R, Werner C, Mann D, D’Elia J, Silva $P$ : Effects of saline, mannitol, and furosemide to prevent acute decreases in renal function induced by radiocontrast agents. $\mathrm{N}$ Engl J Med 1994;331:1416-1420.

-12 Safirstein R, Andrade L, Vieira JM: Acetylcysteine and nephrotoxic effects of radiographic contrast agents - a new use for an old drug. N Engl J Med 2000;343:210-212.

-13 Tepel M, van der Giet M, Schwarzfeld C, Laufer U, Liermann D, Zidek W: Prevention of radiographic-contrast-agent-induced reductions in renal function by acetylcysteine. N Engl J Med 2000;343:180-184.

-14 Brar SS, Shen AY, Jorgensen MB, Kotlewski A, Aharonian VJ, Desai N, Ree M, Shah AI, Burchette RJ: Sodium bicarbonate vs. sodium chloride for the prevention of contrast medium-induced nephropathy in patients undergoing coronary angiography: a randomized trial. JAMA 2008;300:1038-1046.

-15 Dussol B, Morange S, Loundoun A, Auquier $\mathrm{P}$, Berland Y: A randomized trial of saline hydration to prevent contrast nephropathy in chronic renal failure patients. Nephrol Dial Transplant 2006;21:2120-2126.
16 Marenzi G, Assanelli E, Marana I, Lauri G, Campodonico J, Grazi M, De Metrio M, Galli S, Fabbiocchi F, Montorsi P, Veglia F, Bartorelli AL: N-acetylcysteine and contrast-induced nephropathy in primary angioplasty. N Engl J Med 2006;354:2773-2782.

17 Birck R, Krzossok S, Markowetz F, Schnulle P, van der Woude FJ, Braun C: Acetylcysteine for prevention of contrast nephropathy: meta-analysis. Lancet 2003;362:598-603.

18 Pannu N, Manns B, Lee H, Tonelli M: Systematic review of the impact of n-acetylcysteine on contrast nephropathy. Kidney Int 2004;65:1366-1374.

19 Kelly AM, Dwamena B, Cronin P, Bernstein SJ, Carlos RC: Meta-analysis: effectiveness of drugs for preventing contrast-induced nephropathy. Ann Intern Med 2008;148:284294.

-20 Salom MG, Ramirez P, Carbonell LF, Lopez Conesa E, Cartagena J, Quesada T, Parrilla P, Fenoy FJ: Protective effect of N-acetyl-L-cysteine on the renal failure induced by inferior vena cava occlusion. Transplantation 1998; 65:1315-1321.

21 Mazzon E, Britti D, De Sarro A, Caputi AP, Cuzzocrea S: Effect of N-acetylcysteine on gentamicin-mediated nephropathy in rats. Eur J Pharmacol 2001;424:75-83.

22 Tariq M, Morais C, Sobki S, Al Sulaiman M, Al Khader A: N-acetylcysteine attenuates cyclosporin-induced nephrotoxicity in rats. Nephrol Dial Transplant 1999;14:923-929.

23 DiMari J, Megyesi J, Udvarhelyi N, Price P, Davis R, Safirstein R: N-acetyl cysteine ameliorates ischemic renal failure. Am J Physiol 1997;272:F292-F298.

24 Heyman SN, Goldfarb M, Shina A, Karmeli F, Rosen S: N-acetylcysteine ameliorates renal microcirculation: studies in rats. Kidney Int 2003;63:634-641.

25 Terlouw SA, Masereeuw R, Russel FG, Miller DS: Nephrotoxicants induce endothelin release and signaling in renal proximal tubules: effect on drug efflux. Mol Pharmacol 2001;59:1433-1440.

26 Margulies KB, Hildebrand FL, Heublein DM, Burnett JC Jr: Radiocontrast increases plasma and urinary endothelin. J Am Soc Nephrol 1991;2:1041-1045.

27 Heyman SN, Brezis M, Reubinoff CA Greenfeld Z, Lechene C, Epstein FH, Rosen $\mathrm{S}$ : Acute renal failure with selective medullary injury in the rat. J Clin Invest 1988;82: 401-412.

28 Heyman SN, Brezis M, Epstein FH, Spokes K, Silva P, Rosen S: Early renal medullary hypoxic injury from radiocontrast and indomethacin. Kidney Int 1991;40:632-642.

29 Welch WJ, Deng X, Snellen H, Wilcox CS: Validation of miniature ultrasonic transittime flow probes for measurement of renal blood flow in rats. Am J Physiol 1995; 268:F175-F178.
30 Hansell P: Evaluation of methods for estimating renal medullary blood flow. Ren Physiol Biochem 1992;15:217-230.

31 Weisberg LS, Kurnik PB, Kurnik BR: Radiocontrast-induced nephropathy in humans: role of renal vasoconstriction. Kidney Int 1992;41:1408-1415

32 Prasad PV, Priatna A, Spokes K, Epstein FH: Changes in intrarenal oxygenation as evaluated by bold MRI in a rat kidney model for radiocontrast nephropathy. J Magn Reson Imaging 2001;13:744-747.

>33 Porter GA: Contrast-associated nephropathy: presentation, pathophysiology and management. Miner Electrolyte Metab 1994; 20:232-243.

34 Conesa EL, Valero F, Nadal JC, Fenoy FJ, Lopez B, Arregui B, Salom MG: N-acetyl-Lcysteine improves renal medullary hypoperfusion in acute renal failure. Am J Physiol Regul Integr Comp Physiol 2001;281:R730R737.

35 Caldicott WJ, Hollenberg NK, Abrams HL: Characteristics of response of renal vascular bed to contrast media: evidence for vasoconstriction induced by renin-angiotensin system. Invest Radiol 1970;5:539-547.

>36 Katzberg RW, Schulman G, Meggs LG, Caldicott WJ, Damiano MM, Hollenberg NK: Mechanism of the renal response to contrast medium in dogs: decrease in renal function due to hypertonicity. Invest Radiol 1983;18: 74-80.

37 Aspelin P, Aubry P, Fransson SG, Strasser R, Willenbrock R, Berg KJ: Nephrotoxic effects in high-risk patients undergoing angiography. N Engl J Med 2003;348:491-499.

-38 Rudnick MR, Goldfarb S, Wexler L, Ludbrook PA, Murphy MJ, Halpern EF, Hill JA, Winniford M, Cohen MB, Van Fossen DB: Nephrotoxicity of ionic and nonionic contrast media in 1,196 patients: a randomized trial. The Iohexol Cooperative Study. Kidney Int 1995;47:254-261.

$\checkmark 39$ Alonso A, Lau J, Jaber BL, Weintraub A, Sarnak MJ: Prevention of radiocontrast nephropathy with $\mathrm{N}$-acetylcysteine in patients with chronic kidney disease: a meta-analysis of randomized, controlled trials. Am J Kidney Dis 2004;43:1-9.

40 Boesgaard S, Aldershvile J, Poulsen HE, Christensen S, Dige-Petersen H, Giese J: Nacetylcysteine inhibits angiotensin converting enzyme in vivo. J Pharmacol Exp Ther 1993;265:1239-1244.

-41 Girouard H, Chulak C, Wu L, Lejossec M, de Champlain J: N-acetylcysteine improves nitric oxide and alpha-adrenergic pathways in mesenteric beds of spontaneously hypertensive rats. Am J Hypertens 2003;16:577-584.

-42 Nitescu N, Grimberg E, Ricksten SE, Guron $\mathrm{G}$ : Effects of $\mathrm{N}$-acetyl-L-cysteine on renal haemodynamics and function in early ischaemia-reperfusion injury in rats. Clin Exp Pharmacol Physiol 2006;33:53-57. 
43 Emch TM, Haller NA: A randomized trial of prophylactic acetylcysteine and theophylline compared with placebo for the prevention of renal tubular vacuolization in rats after iohexol administration. Acad Radiol 2003;10:514-519.

-44 Hoffmann U, Fischereder M, Kruger B, Drobnik W, Kramer BK: The value of N-acetylcysteine in the prevention of radiocontrast agent-induced nephropathy seems questionable. J Am Soc Nephrol 2004;15: 407-410.

45 Yanagisawa M, Kurihara H, Kimura S, Tomobe Y, Kobayashi M, Mitsui Y, Yazaki Y, Goto K, Masaki T: A novel potent vasoconstrictor peptide produced by vascular endothelial cells. Nature 1988;332:411-415.

46 Heyman SN, Clark BA, Kaiser N, Spokes K, Rosen S, Brezis M, Epstein FH: Radiocontrast agents induce endothelin release in vivo and in vitro. J Am Soc Nephrol 1992;3:58-65.

47 Bird JE, Giancarli MR, Megill JR, Durham SK: Effects of endothelin in radiocontrastinduced nephropathy in rats are mediated through endothelin-A receptors. J Am Soc Nephrol 1996;7:1153-1157.

48 Liss P, Carlsson PO, Nygren A, Palm F, Hansell P: ET-a receptor antagonist bq123 prevents radiocontrast media-induced renal medullary hypoxia. Acta Radiol 2003;44: 111-117.

49 Pollock DM, Polakowski JS, Wegner CD, Opgenorth TJ: Beneficial effect of ETA receptor blockade in a rat model of radiocontrast-induced nephropathy. Ren Fail 1997; 19:753-761.
50 Wang A, Holcslaw T, Bashore TM, Freed MI, Miller D, Rudnick MR, Szerlip H, Thames MD, Davidson CJ, Shusterman N, Schwab SJ: Exacerbation of radiocontrast nephrotoxicity by endothelin receptor antagonism. Kidney Int 2000;57:1675-1680.

51 Beeri R, Symon Z, Brezis M, Ben-Sasson SA, Baehr PH, Rosen S, Zager RA: Rapid DNA fragmentation from hypoxia along the thick ascending limb of rat kidneys. Kidney Int 1995;47:1806-1810.

52 Hizoh I, Strater J, Schick CS, Kubler W Haller C: Radiocontrast-induced DNA fragmentation of renal tubular cells in vitro: role of hypertonicity. Nephrol Dial Transplant 1998;13:911-918.

-53 Hizoh I, Haller C: Radiocontrast-induced renal tubular cell apoptosis: hypertonic versus oxidative stress. Invest Radiol 2002;37:428434.

54 Zager RA, Johnson AC, Hanson SY: Radiographic contrast media-induced tubular injury: evaluation of oxidant stress and plasma membrane integrity. Kidney Int 2003;64: 128-139.

55 Jost G, Pietsch H, Lengsfeld P, Hutter J, Sieber MA: The impact of the viscosity and osmolality of iodine contrast agents on renal elimination. Invest Radiol 2010;45:255261.
56 Seeliger E, Becker K, Ladwig M, Wronski T, Persson PB, Flemming B: Up to 50-fold increase in urine viscosity with iso-osmolar contrast media in the rat. Radiology 2010; 256:406-414.

57 Seeliger E, Flemming B, Wronski T, Ladwig M, Arakelyan K, Godes M, Mockel M, Persson PB: Viscosity of contrast media perturbs renal hemodynamics. J Am Soc Nephrol 2007; 18:2912-2920.

58 Liss P, Persson PB, Hansell P, Lagerqvist B: Renal failure in 57,925 patients undergoing coronary procedures using iso-osmolar or low-osmolar contrast media. Kidney Int 2006;70:1811-1817.

-59 Heinrich MC, Haberle L, Muller V, Bautz W, Uder M: Nephrotoxicity of iso-osmolar iodixanol compared with nonionic low-osmolar contrast media: meta-analysis of randomized controlled trials. Radiology 2009; 250:68-86.

60 Jo SH, Youn TJ, Koo BK, Park JS, Kang HJ, Cho YS, Chung WY, Joo GW, Chae IH, Choi DJ, Oh BH, Lee MM, Park YB, Kim HS: Renal toxicity evaluation and comparison between visipaque (iodixanol) and hexabrix (ioxaglate) in patients with renal insufficiency undergoing coronary angiography - the recover study: a randomized controlled trial. J Am Coll Cardiol 2006;48:924-930.

-61 From AM, Bartholmai BJ, Williams AW, McDonald FS: Iodixanol compared to iohexol for contrast procedures: a case-matched retrospective cohort study. Acta Radiol 2008;49:409-414. 